\title{
Research on Marketing Strategy for A Ketogenic Food Start Up Business in Bandung
}

\author{
Vania Arini Putri and Budi Permadi Iskandar
}

\begin{abstract}
Many people feel it is necessary to have a slender body and pursuing it through various ways, including diet. The ketogenic diet is a low-carb and high-fat diet and has been proven to be one of the effective diets to lose weight. The preliminary research shows the lack of choices of pure ketofriendly food on the market is the main problem of keto dieters. This is seen as a good opportunity from a business perspective and further research was conducted. The research was done using a qualitative method in-depth interviews to gain perspective on how to market a ketogenic food provider. The respondents are those who have dieted and have had a problem in body weight. There are 7 out of 8 respondents said they would consider doing the keto diet in the future. This research results that the suitable target consumers are people with age of 22-35

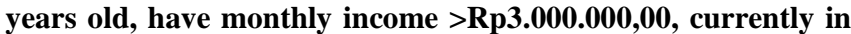
college and college graduate, student, and employee, in upper middle social class, have interests in weight loss and delicious food, and body goals oriented. The personas for this target market are lazy dieters, weight loss achievers, and experimental dieters. The result for marketing strategy is a 4P marketing mix. The products are keto-friendly heavy meals and desserts. The

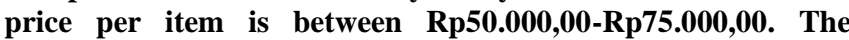
consumers can make the purchase online. The promotions are educational and informative contents, endorsement, paid promote, discount, and cheaper price for weekly meal plan purchase.
\end{abstract}

Index Terms - Culinary, In-depth Interviews, Ketogenic Diet, Marketing Mix, Qualitative Method, Start Up, STP.

\section{INTRODUCTION}

Slender body is generally associated with happiness, success, youthfulness, and acceptability. People feel it is necessary to conform to this standard and pursuing it through various ways. The dieting industry is the perfect industry because it realizes this problem of body dissatisfaction and offers to solve it. The ketogenic diet is a low-carb and highfat diet that is proven to be very effective for losing weight. The preliminary research conducted to people who have undergone the keto diet, and it results that the lack of choices of pure keto-friendly food on the market becomes their main problem. This is seen as a good opportunity from a business perspective and further research was conducted.

The objectives of this research are to identify the attitude of diet consumers in Bandung towards the ketogenic diet concept, identify the suitable target market, and create a marketing strategy for a ketogenic food provider business in Bandung.

The research was conducted using a qualitative method indepth interviews in order to gained perspective on how to

Published on December 22, 2020.

Vania Arini Putri, Bandung Institute of Technology, Bandung, Indonesia. (e-mail: vania.arini@sbm-itb.ac.id) market a ketogenic food provider. The respondents in this research are people who have been on a diet before. The research showed that people who have dieted before are already familiar with the concept of reducing carbohydrates and sugar consumption for weight loss, even some of them have tried a low carb diet. These diet consumers dislike diet methods that are restrictive, have tasteless foods, and make them starve. Because they find it hard to leave fatty foods and meat in their diet, 7 out of 8 diet consumers of this research said they would consider doing the keto diet to lose weight in the future. The result of this research shows that the suitable target consumers for this business are people in their early adulthood who are still single and have not start their own family. These people are in the age of 22-35 years old, have monthly income above Rp3.000.000,00, currently in college and college graduate, student, and employee, and in upper middle social class. They have interests in weight loss and delicious food, and body goals oriented. The personas that suit this target market are lazy dieters, weight loss achievers, and experimental dieters.

The marketing strategy for this business consists of $4 \mathrm{P}$ marketing mix that is based on the needs of the target market. The product for this business should include both heavy meals and desserts that are keto-friendly. The price per item is ranged from $\mathrm{Rp} 50.000,00-\mathrm{Rp} 75.000,00$, and there should be an option of weekly meal plan. The consumers can make the purchase online via Instagram, WhatsApp, Gofood/Grabfood. The promotion for this business includes educational and informative contents on Instagram, endorsement, paid promote, discount, and cheaper price for weekly meal plan purchase.

\section{LITERATURE REVIEW}

\section{A. Diet for Weight Loss}

Some people diet because they are overweight, while some of them do it for aesthetic reasons [1]. When someone experiences a calorie deficit from exercising or reducing food intake, it will lead to weight loss. A formula states the proportion of weight loss consists of $80 \%$ diet and $20 \%$ exercise.

\section{B. The Ketogenic Diet}

The ketogenic diet is a type of diet that is extremely rich in fat and has a very strict focus on low carbohydrate consumption. People are doing this diet to reduce the excess body weight. The rule of percentage intake of nutrients that

Budi Permadi Iskandar, Bandung Institute of Technology, Bandung, Indonesia.

(e-mail: bpi@sbm-itb.ac.id) 
should be followed by its dieters are $5-20 \%$ proteins, $70-75 \%$ fats, and 5-15\% carbohydrates [2].

\section{Consumer Behavior}

Consumer behavior is a study about individual, group, and organization in choosing, buying, using, and dispose goods, services, and ideas, or experiences to fulfill their needs and wants [3].

\section{Marketing Research}

Marketing research is classified into problemidentification research and problem-solving research. The research designs in marketing research can be either exploratory or conclusive type. Exploratory research is conducted to explore the problem situation and to gain ideas and insight into the problem [4].

\section{E. Marketing Strategy}

A marketing strategy is made to determine which consumers will be served and how the company will create value for consumers. A collection of marketing tools used to implement a marketing strategy is known as marketing mix, which is divided into four groups called the 4Ps [5].

\section{F. Market Segmentation}

Market segmentation is the activity of identifying and dividing the market into several groups of consumers who want or need a variety of the same product or service. Market can be divided based on geographic, demographic, psychographic, and behavioral [3].

\section{G. Market Targeting}

Market targeting is the activity of evaluating several market segments and decide which segment the company will serve. In evaluating the market segments, a company must pay attention to two things, those are segment attractiveness and company fit. An effective market segments must have these characteristics: measurable, substantial, accessible, differentiable [3].

\section{H. Market Positioning}

Market positioning is the activity of arranging a product so that it has a clear, special, and desirable place in the minds of consumers. A company must be careful in choosing what will set it apart from the competitors. A difference is feasible to make if it meets the following criteria: important, distinctive, superior, communicable, pre-emptive, affordable, profitable [5].

\section{Methodology}

This research starts with a preliminary study that was conducted to people who have done the ketogenic diet to discover the problems faced by keto dieters while doing the diet. After the problem was defined, several literatures were reviewed to conduct the research. The data in this research is collected using a qualitative method by conducting in-depth interviews. The purposes of the qualitative data collection are to understand the consumers attitudes toward the ketogenic diet concept and identify the proper way to approach consumers. In this study, the qualitative data collection is divided into two parts to reach each purpose. The first qualitative data collection was done to 8 people, and the second qualitative data collection was done to respondents who were in the first qualitative data collection who are interested in the ketogenic diet concept.

\section{FINDINGS AND ARGUMENT}

\section{A. Respondents Behavior}

The respondents are those who are health-conscious and have interest in weight loss. This makes majority of the respondents already know many types of diets. Theses respondents are already familiar with the type of diet that reduces carbohydrates intake, sweet drinks, and even cut the rice consumption, which are close to the ketogenic diet concept. Most of these respondents last went on a diet 1-2 years ago and more than 2 years ago, and mostly only lasted for less than 3 months doing the diet.

\section{B. Respondents Motivation in Dieting}

The most popular reason why these respondents go on a diet is to lose weight and they are motivated by how they look. While they are self-motivated, they are committed and disciplined while doing a diet. The challenging issue for them is the environment, which not all of them are also in a diet.

\section{Respondents Preferences in Diet and Attitude Towards the Ketogenic Diet Concept}

These respondents are interested in a diet if it is easy to follow and can make them healthier. The things they do not like about most diets are the food restriction, the tasteless foods, and the starvation. The respondents said that they feel it is hard to leave out fatty foods and meats. The concept which makes the dieters consume a lot of fats make them feel curious of the diet. The last question asked if they will one day consider doing the ketogenic diet, 7 people said yes $(87,5 \%)$ and 1 person said no $(12,5 \%)$.

\section{Consumers Decision Making Process}

All of the respondents are still single or unmarried. This is shown by the responses to the question that asked what can influence them in doing a diet, their answer is themselves. The pre-purchase and the purchase decision depend on the individuals themselves.

\section{E. Identify Consumers Buying Power}

The highest percentage of income are people whose income is $>\mathrm{Rp5} .000 .000,00$ a month. The price of foods for diet is typically higher than regular foods. This makes the author to ask the respondents about how much money they would spend on a diet food. Half of the respondents gave answer that they are only willing to spend their money on the range of $\mathrm{Rp50.000,01-Rp75.000,00} \mathrm{on} \mathrm{a} \mathrm{diet} \mathrm{food.}$

\section{F. Product}

The result shows that the composition of people who prefer to buy ready-to-eat meals is the same as composition of people who prefer to prepare or cook their own foods. The respondents were asked will they consider buying ready-toeat meals from a diet food provider, and $85 \%$ were positive or willing to consider it. The types of foods they most prefer are Western foods, Indonesian foods, and Japanese foods. 
Most respondents regularly eat each day and they still consider snacking important.

\section{G. Point of Sale}

The author wants to know where to sell the products and the necessity of having an offline store. The result shows that the most important thing to have is an Instagram account. The next most important thing is the availability in GoFood or Grabfood and WhatsApp contact.

\section{H. Way of Promotion}

For awareness, almost all of the respondents agree that Instagram Ads is the most influential way of promotion. For sales, the interesting thing for respondents is a bundling package. The next important things of way of sale promotion are discount and meal plans.

\section{Competitors Analysis}

There are four competitors that were analyzed, which are Ketofastosisfood, Bandung Ketogenic 101, Delicieux Catering, and The Signature. Three out of four competitors focus on giving alternatives for keto dieters who are unable to consume flour-based foods and making desserts as their main products, while one competitor focuses on weekly meal plan and promising weight loss to its consumers. The similarity of these competitors is in their price, which is premium. The high price is probably caused by the high price of the food materials that are used and also they only offer big portions in the menu.

\section{J. Segmentation}

The segmentation is done based on the geographical, demographical, psychographics, and behavioral aspects. In the geographical, the author divided the customers based on the domicile and area. The demographical aspects that are used are age, gender, monthly income, educational level, marital status, occupation, and social class. The psychographics aspect divide customers based on the interest and lifestyle. The behavioral variables used in this segmentation are benefits, and occasions, and user status.

\section{K. Targeting}

The targeting is shown in the Table 1. Based on the target segment, the author makes personas to describe the segments in human form. The first one is Lazy Dieters, which are people who want to lose weight, but they do not like to eat foods that are usually included in the common diets. These people are used to fatty and delicious foods. The second one is Weight Loss Achievers. These people put a lot of efforts to lose weight. With their strong will to lose weight, they are able to commit to restrictive diet methods. The third persona is Experimental Dieters. These people focused to control what they eat in order to achieve their body goals and have tried many different types of diets in their lives.
TABLE I: TARGETING

GEOGRAPHICS
Bandung
Urban
DEMOGRAPHICS
22-35 years old
Men, Women
Above Rp3.000.000
In college, college graduate
Single
Students, Employee
Upper middle class
Weight loss, delicious food
Body goals oriented
PSYCHOGRAPHICS loss, healthy
Special occasion
Potential user, first timer

\section{Positioning}

The positioning for this business is done based on three aspects, those are value, type of product, and price. First, this business can meet the needs of people who want to lose weight by following the keto diet method without having to worry about the ingredients used would violate the dietary restrictions. Second, this business has a variety of products consisting of heavy meals and snacks. The third one, this business has product price that is more affordable. The Points-of-difference (PODs) is this business sells heavy meals and snacks for the ketogenic diet with more affordable price. The Points-of-parity (POPs) of this business and its competitors is to meet the dietary needs of keto dieters to lose weight.

In the targeting section, it was mentioned that there are three personas for this business, which are Lazy Dieters, Weight Loss Achievers, and Experimental Dieters. Those personas have unique characteristics, so the author developed a more detailed positioning to attract each of the personas. The general positioning for Business $\mathrm{X}$ is the low price and high versatility, but here is more specific positioning that are designed based on the three personas.

\section{Tasteful Diet}

This positioning is specifically made for the first persona, the Lazy Dieters. This states that the ketogenic diet includes tasty foods in its diet method. Because the lazy dieters dislike the foods that are commonly included in other diet methods (vegetables, fruits, tasteless foods). The "tasteful diet" positioning is suitable for this persona because these people are assured that they are still doing a diet method for their weight loss even though the foods are tasty.

\section{Effortless Weight Loss}

The second persona, Weight Loss Achievers is the most effortful in losing weight compared to the other two personas. This "effortless weight loss" positioning shows this persona that doing the keto diet makes their weight loss journey becomes easier, because this diet method can be effective without having to do exercise excessively. With the "effortless" positioning, this persona can allocate the time and energy they usually put on exercising on other things they can enjoy. This "effortless" also means that the diet method can still be enjoyable because of the food choices.

\section{New Diet Experience}

Besides their goal to lose weight, the Experimental Dieters enjoy trying different types of diets. Unlike other types of diet 
methods, the keto diet includes a high consumption of fat in order to achieve the weight loss. The ketogenic diet changes our body metabolism by burning fat as the main energy source instead of carbohydrates. This shows how different the ketogenic diet compared to other diets, which will give a new experience in dieting.

\section{Marketing Mix}

The marketing mix consists of $4 \mathrm{P}$ which is product, price, place, and promotion. The proposed marketing mix for this business is shown in Table 2 .

TABLE 2: PROPOSED MARKETING MiX

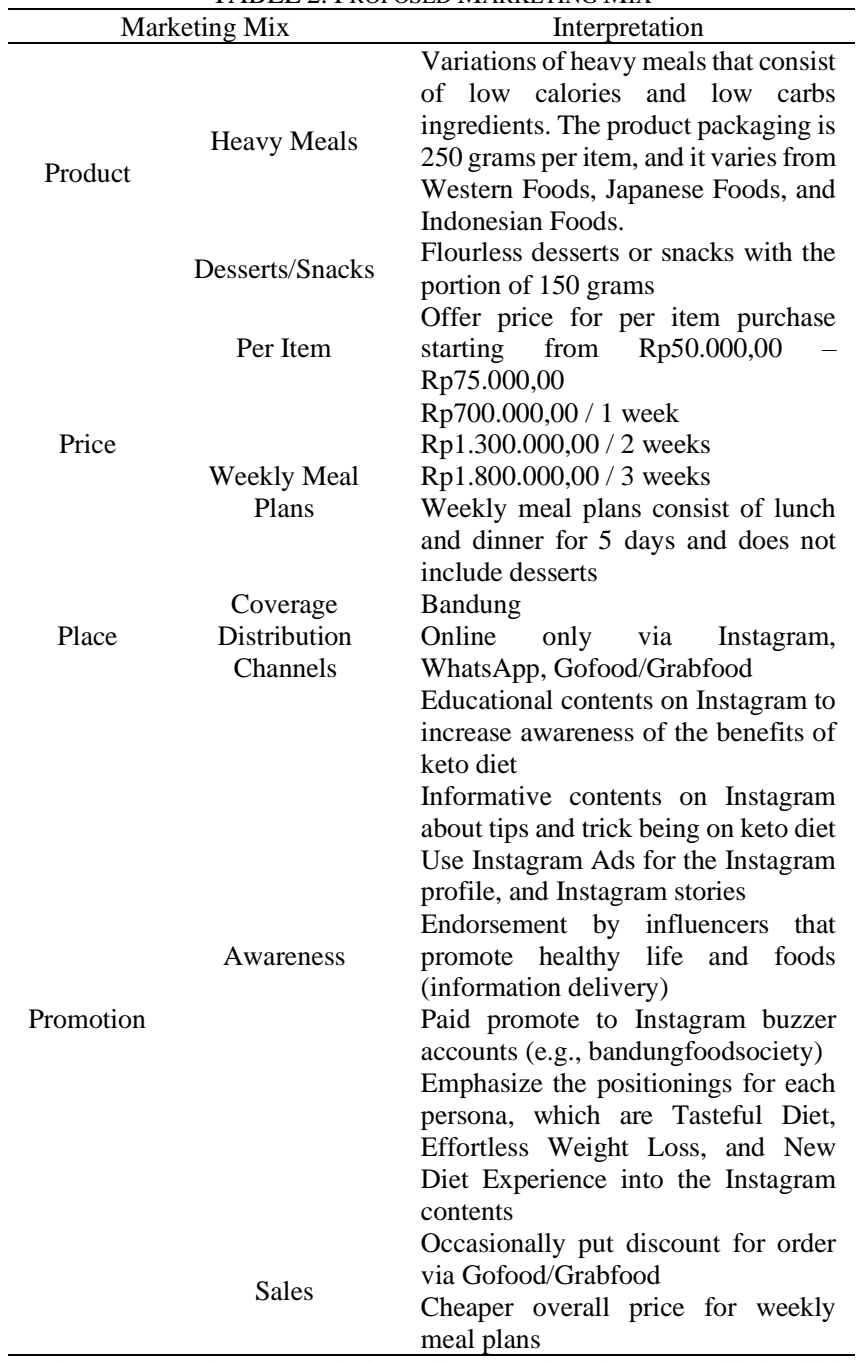

Product - Focused on one main ingredient to reduce the costs, which will be the shirataki noodles.

Price - Because of the gap between how much money the consumers are willing to spend and the price offered in the market, this business choose the cost leadership strategy, to encourage people to try keto diet and to compete with the competitors.

Place - Available by online purchase because of the interview results and cost reduction.

Promotion - The contents will include information regarding the keto diet. To reduce the costs, the designers could be those who are still in the college and will be paid per design. The promotional contents will be 3 contents per week, and the rests are product photos. For the paid promote and endorsement of the business, the author suggests Business X to choose micro influencers with the targeting audience are into healthy life via sociobuzz.com.

\section{CONCLUSION AND RECOMMENDATION}

\section{A. Conclusion}

The concept of the ketogenic diet is unlike any other diets that the society is already familiar with. There are many reasons that can make people be on a diet, but most people do it for a same reason, which is to achieve their weight goals. In the preliminary research, it was proven that this low-carbs high-fat diet method is effective for weight loss. Although with its effectivity, there is a wide choice of diet methods that people can choose, and people are more likely to choose one that is more suitable for them.

The reason why the research was done to people who have dieted is because they have or had a problem regarding their body weight, which makes them more potential as consumers. All of the participants are in their early adulthood and still single. People who have not started a family are considered of being more independent and they are more likely to rely on themselves while making decisions, including their diets. Because they are not married yet, these people are more concerned about how they look. They are willing to put more effort to look good, and they have the time for it.

According to the analysis and discussion of the data, below is the research conclusion to answer each research question. RQ1: What is the attitude of diet consumers in Bandung towards the concept of the ketogenic diet?

Based on the research, the respondents are already familiar with the concept of reducing carbs and sugar consumption for weight loss. These diet consumers are mostly self-motivated, they are mostly committed when doing a diet. The result showed that 7 out of 8 respondents said that they would consider keto diet as an alternative to lose weight.

RQ2: Who is the suitable target market for a ketogenic food provider business in Bandung?

The suitable target market for this business are single men and women in urban area of Bandung who are 22-35 years old, with monthly income >Rp3.000.000,00, educational level in college and college graduate, student, and employee, and in upper middle social class. This target market has interests in weight loss and delicious food, and body goals oriented. With their goals to lose weight, they also want to have a benefit of being healthier. They buy the products on special occasion on times they want to lose weight. The target market is people who have tried other diet methods before, and people who just begun to do the keto diet. The personas that are suitable for this target markets are lazy dieters, weight loss achievers, and experimental dieters.

RQ3: What is the proposed marketing strategy for a ketogenic diet food provider business in Bandung to attract consumers in doing the keto diet?

The marketing strategy for this business consists of $4 \mathrm{P}$ marketing mix that is based on the needs of the target market. The product includes keto-friendly heavy meals and desserts. The price per item is from Rp50.000,00-Rp75.000,00, and there is a of weekly meal plan option. The consumers can make the purchase online via Instagram, WhatsApp, Gofood/Grabfood. The promotion for this business includes educational and informative contents, endorsement, paid promote, discount, and cheaper price for weekly meal plan purchase. 


\section{B. Recommendation}

The author gives recommendation for further research in this topic. According to the result of this study, these are some suggestions that can be considered for future research.

1. This research only includes the qualitative method on the diet consumers. The future research could use quantitative analysis to get a conclusive finding.

2. This research results in marketing mix for a ketogenic food provider business. The future research can focus on the branding aspects of the business.

3. This research includes non-user of the ketogenic diet as respondents. The future research can use the user of the keto diet as samples in accordance with the preliminary research result that the long-term keto dieters will not recommend to others.

\section{REFERENCES}

[1] Grogan, S., 2017, Body Image: Understanding Body Dissatisfaction in Men, Women and Children, New York, Routledge.

[2] Rowe, M., 2017, Ketogenic Diet Food: Avoid Ketogenic Diet Mistakes: Beginner Guide for Weight Loss: Includes Delicious Ketogenic Diet Recipes, Pronoun.

[3] Kotler, P., \& Keller, K. L., 2015, Marketing Management $15^{\text {th }}$ Edition, Boston [etc.], Pearson.

[4] Malhotra, N. K., 2011, Basic Marketing Research: Integration of Social Media $4^{\text {th }}$ Edition, Boston [etc.], Pearson.

[5] Kotler, P., Armstrong, G., Saunders, J., Wong, V., 2005, Principle of Marketing $4^{\text {th }}$ Edition, New Jersey, Prentice-Hall, Inc.

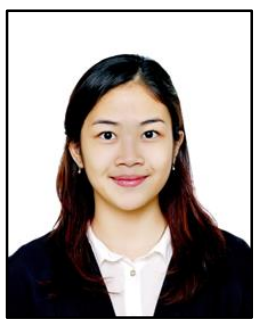

Vania Arini Putri was born in Surabaya, $27^{\text {th }}$ of September 1995. She earned her bachelor degree in Industrial Engineering from Parahyangan Catholic University Bandung. She pursued her Master Degree in Business Administration at Institut Teknologi Bandung and majoring in Entrepreneurship-Track. She has work experience in PT Ayo Media Network in 2018 as a Human Resource Manager and did an internship program from November February 2020 at Tribe Commerce of PT Telkom Digital Service Division.

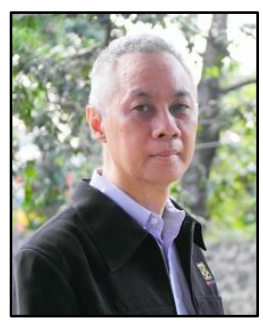

Budi Permadi Iskandar is a faculty member at the School of Business and Management, Bandung Institute of Technology (SBM ITB) $\mathrm{He}$ had his bachelor and master degree in Urban and Regional Planning at Institut Teknologi Bandung. After leaving a bankrupt company, he continued his training in Industrial Engineer and Regional and Urban Planning. He then started his teaching career at the Regional and Urban Planning Program. 17 years later he was assigned to the School of Business and Management, with a short special assignment to lead a school in Jakarta. He is currently teaching Management Practice at the Undergraduate Level and Marketing Management at Graduate Level. 